\title{
Borsa Likiditesi ile Ekonomik Büyüme Arasındaki İlişki: Borsa İstanbul Örneği ${ }^{1}$
}

\author{
Özlem ÖZTÜRK ÇETANAK \\ Dr. Öğr. Üyesi, Niğde Ömer Halisdemir Üniversitesi, \\ İktisadi ve İdari Bilimler Fakültesi, İktisat Bölümü \\ ozlemcetenak@ohu.edu.tr \\ Orcid ID: https://orcid.org/0000-0003-2014-0740
}

\author{
Özkan HAYKIR \\ Dr. Öğr. Üyesi, Niğde Ömer Halisdemir Üniversitesi, \\ İktisadi ve İdari Bilimler Fakültesi, Bankacılık ve Finans Bölümü \\ ohaykir@ohu.edu.tr \\ Orcid ID: https://orcid.org/0000-0003-2800-8699
}

\begin{abstract}
$\ddot{\mathbf{O z}}$
Finansal gelişme ve ekonomik büyüme arasındaki ilişkiyi araştıran oldukça geniş bir literatür vardır. Çalışmalar genellikle yaygın olarak bilinen para ve kredi ile ilgili büyüklüklerde yaşanan gelişmelerin ekonomik büyüme üzerindeki etkisine odaklanmıştır. Ancak finansal piyasalarda faaliyet gösteren kurumlar ve işlem gören araçlar oldukça çeşitlidir. Özellikle borsalar finansal piyasaların önemli bir ayağıdır. Etkin çalışan borsalar sermayenin tabana yayılmasına hizmet edip, aynı zamanda tasarruf sahiplerine riski çeşitlendirme imkanı sağlar. Buna ek olarak borsalar, firmaların yeni yatırım ya da genişleme yolunda karşılaştıkları finansman sorunlarına düşük maliyetlerle çözüm getirirler. Borsanın etkinliğinin ölçümünde genellikle piyasa büyüklüğü ve piyasa kapitalizasyonu değişkenleri kullanılmaktadır. Ancak son yıllarda piyasa likiditesi de en iyi ölçüm araçlarından biri olarak kabul edilmektedir. Bu çalışmada finansal gelişmenin bir göstergesi olan borsa likiditesi ile ekonomik büyüme arasında bir nedensellik ilişkisinin olup olmadığı araştırılmıştır. Bu amaçla çalışmada Türkiye için 1995:Q1 - 2018:Q1 dönemi için BIST-100 endeksinin likiditesi ve büyüme oranı değişkenleri kullanılarak Granger nedensellik testi uygulanmıştır. Yapılan testlerde, borsa likiditesindeki artışın ekonomik büyümeyi pozitif etkilediği,
\end{abstract}

\footnotetext{
${ }^{1}$ Makale Geliş/Kabul Tarihi: 11.04.2019 / 22.08.2019

Künye Bilgisi: Öztürk Çetenak, Ö., Haykır, Ö. (2019). Borsa Likiditesi ile Ekonomik Büyüme Arasındaki İlişki: Borsa Istanbul Örneği. Kahramanmaraş Sütçü İmam Üniversitesi Sosyal Bilimler Dergisi, 16 (2), 576-591. DOI: 10.33437/ksusbd.552463
} 
ancak ekonomik büyümenin borsa likiditesi üzerinde anlamlı bir etkisinin olmadığ sonucuna ulaşılmıştır.

Anahtar Kelimeler: Finansal Gelişme, Ekonomik Büyüme, Likidite, Borsa İstanbul.

\title{
The Relation between Stock Market Liquidity and Economic Growth: Example of Borsa İstanbul
}

\begin{abstract}
There is a vast literature on the link between financial development and economic growth. Studies are generally focused on the effect of the developments in money and credit on economic growth. However, the financial institutions and the instruments operating in the financial markets are quite diverse. Especially, the stock markets are an essential pillar of the financial markets. The efficient stock markets help to spread the capital to the base as well as allow the investor to diversify the risk. Moreover, the stock markets provide solutions to the financial problems faced by firms in new investment or expansion at low cost. Market size and market capitalization variables are generally used in the measurement of the stock market efficiency. However, in recent years, market liquidity is considered as one of the best proxies of the efficiency of the stock market. In this study, it was investigated whether there is a relationship between stock market liquidity as an indicator of financial development and economic growth. For this purpose, we implement the Granger causality test to the period between 1995: Q1 - 2018: Q1 using BIST-100 index liquidity and growth rate for Turkey. As a result, it was shown that the increase in stock liquidity had a positive impact on economic growth, but economic growth had no significant effect on the liquidity of the stock market.
\end{abstract}

Keywords: Financial Development, Economic Growth, Liquidity, Borsa Istanbul.

\section{GİRIŞ}

Bir ülkede kullanılan finansal araçların artması ve bu araçların daha yaygın kullanılabilir hale gelmesi finansal gelişme olarak tanımlanmaktadır. Patrick (1966), finansal gelişme ve ekonomik büyüme arasındaki ilişkiyi ilk kavramsallaştıran kişi olmuş ve "arz öncüllü" ve "talep takipli" olmak üzere iki hipotez geliştirmiştir. Patrick (1966, s.174-175)'e göre talep takipli durum, reel sektörün gelişmesi ve böylece finansal hizmetlere olan talebinin artmas1 sonucunda finansal sistemin gelişmesini ifade etmektedir. Arz öncüllü durum ise, finansal sektörde yaşanan gelişmelerin işlem ve aracılık maliyetlerini düşürerek 
yatırımları daha az maliyetle finanse etmeye olanak sağladığı ve böylece yatırımları ve dolayısıyla ekonomik büyümeyi artırdığı duruma karşılık gelmektedir.

Kaynak tahsisini kolaylaştırması ve yatırım maliyetlerini azaltması açısından önemli bir role sahip finansal sistemin gelişmesi basit bir tanımla finansal sistemin yapısının ve büyüklüğünün değişmesidir. Bir bütün olarak finansal sistemin gelişmesi kavramı, detaylara indirgendiğinde finansal sistem içerisinde faaliyet gösteren kurumlar, bu kurumların sağladıkları hizmetler ve sistemde işlem gören araçların çeşit, sayı ve kalitesinde artış anlamına gelmektedir. Finansal gelişme ve ekonomik büyüme ilişkisine dair yazında genellikle bu ilişki para ve kredi büyüklükleri aracılığıyla tartışılmıştır. Ancak özellikle borsalar finansal sistem içerisinde önemli bir yer tutmaktadır.

Borsalar, hisse senetlerinin alım satım işlemlerini yapıldığı kurumsal mekanlardır. Bu piyasalar sermaye oluşumunu ve sermaye tahsisini teşvik eden finansal kuruluşlar olarak tanımlanabilir. Borsalar yeni projelerin finansmanını kolaylaştırarak ya da uzun vadeli borçlanma olanaklarını artırarak, hükümet ve firmaların yatırımlarını modernize etmelerine ve genişletmelerine olanak sağlarlar. Sermayenin verimli ve modern yatırımları yönlendirilmesi kaynak kullanımında etkinlik ilkesinin bir gereğidir. Aksi durumda, ekonomik gelişme zarar görecektir. $\mathrm{Bu}$ nedenle borsaların gelişmesi, finansal gelişmenin bir ayağıdır ve finansal gelişmenin tüm diğer unsurları gibi ekonomik büyüme ile ilişkilidir. Kurumsal firmalar, borsalardan uzun vadeli borç finansmanı ve özkaynak temini ve büyüme için sürekli bir sermaye kaynağı şeklinde yararlanmaktadır. Firmaların finansman sorununa çözüm getiren gelişmiş piyasalar ise ekonomik büyümeye katkı sağlamaktadır.

\section{LITERATÜR TARAMASI}

Finansal sistemin temel işlevi tasarrufların etkin bir biçimde yatırımlara dönüştürülmesini sağlamaktır. $\mathrm{Bu}$ tanımdan yola çıkarak finansal gelişme derecesinin, finansal sistemin bu süreçte oynadığ 1 role göre belirleneceği söylenebilir. Gelişmiş bir finansal sistem tasarruf sahiplerine zengin portföy imkanları sunarak kaynakların etkin dağıtımına ve böylece, yatırımcıların da riski dağıtmasına ve çeşitlendirmesine imkan sağlar. Buna ek olarak gelişmiş finansal sistemler, finansal piyasa aktörleri arasında bilgi akışını kolaylaştırarak bilgi asimetrisi problemini ortadan kaldırırlar.

Finansal gelişme çok boyutlu bir süreçtir. Gertler ve Rose (1994, s. 32) finansal gelişmenin öz finansmandan diş finansmana geçiş, finansal aracılık hizmetlerinin gelişimi, krediye doğrudan erişim imkanlarının artması için piyasaların nihai gelişimi, dünya sermaye piyasalarına daha fazla erişim ve son olarak, risksiz faiz oranlarındaki artışla birlikte mevduat ve kredi faizleri 
arasındaki açıklığın kapanması süreçlerini kapsadığını belirtmiştir (Furstenberg ve Fratianni,1996, s.19).

Tasarruf sahipleri ile yatırımcılar arasında aracilık rolü üstlenen finansal sistem, ekonomik büyümeyi doğrudan değil dolaylı olarak kredi kanalıyla etkilemektedir. Gelişmiş finansal piyasalar yatırım yapmak isteyenlerin dış finansman imkanlarına kolaylıkla ulaşmalarını sağlamakta, bunun sonucunda yatırımlar artmaktadır. Hangi ekonomik gelişme biçimini seçmiş olursa olsun her ülke için artan yatırımlar büyümenin motoru olarak görülmektedir.

Finansal gelişme ekonomik büyümeyi üç yoldan etkileyebilir (Aziz and Duenwald, 2002, s.4):

1. Alternatif yatırım projelerini değerlendirmek için bilgi toplayarak ve risk paylaşarak sermayenin marjinal verimliliğini artırabilir;

2. Finansal aracılık maliyetlerini düşürerek ve verimliliğini artırarak, finansal gelişme yoluyla yatırıma yönlendirilen tasarruf oranını arttırabilir,

3. Özel tasarruf oranını yükseltebilir.

Literatürde finansal gelişmenin kesin olarak ekonomik büyümeyi sağladığına dair bir görüş birliği yoktur. Çalışmaların bir kısmı finansal gelişmenin ekonomik büyümeyi desteklediği sonucuna ulaşsa da farklı sonuçlar üreten çalışmalara da rastlanmaktadır. Ampirik çalışmaların bir kısmı bu iki değişken arasındaki nedensellik ilişkisinin açıklanmasına odaklanmıştır. Finansal gelişme ve ekonomik büyüme arasındaki nedensellik ilişkisinin yönü ile ilgili görüşler dört ana akım üzerinden tartışılmaktadır. $\mathrm{Bu}$ akımlardan en popüler olanları Schumpeter'in öncülük ettiği ve ilişkinin yönünün finansal gelişmeden, ekonomik büyümeye doğru olduğunu ileri sürdüğü akım ve Robinson’un öncülük ettiği ve ilişkinin yönünün ekonomik büyümeden, finansal gelişmeye doğru olduğunu ileri sürdüğü akımdır (Thangavelu vd, 2004, s. 247-248).

Teorik çalışmaların bir kısmı ise A. Lewis' in görüşlerini takip ederek, finansal piyasaların gelişmesinin ekonomik büyümenin bir sonucu olarak ortaya çıktığını ancak gelişen finansal piyasaların da yeniden ekonomik büyümeye yol açtığını savunmaktadır. Böylece bu çalışmalar ekonomik büyüme ve finansal gelişme arasında çift yönlü nedensellik ilişkisi olduğuna dair kanıtlar sunmaktadır (Kirkpatrick ve Green, 2002: 207).

Robert Lucas ise daha az destek bulan bir görüş ileri sürmüş ve ekonominin büyüme sürecinde finansal gelişmenin bir rolü olmadığını iddia etmiştir. Lucas'a göre iktisatçılar, finansal faktörlerin ekonomik büyümedeki rolünü gereğinden 
fazla vurgulamıştır ve gerçekte bu iki değişken arasında bir nedensellik ilişkisi bulunmamaktadır (AlYousif, 2002: 132).

Schumpeter'in (1911) finansal sektörün kredi kanalıyla ekonomik büyümeyi etkilediğini belirttiği çalışması finansal gelişme ve ekonomik büyümeye dair yapılan çalışmaların öncüsü kabul edilebilir. Schumpeter (1911) bu çalışmada, bankacılık sisteminin ekonomik büyümedeki kritik önemini vurgulamı̧ ve bankaların üretken yatırımları tespit edip bu yatırımları finanse ederek yenilikçiliği ve gelecekteki büyümeyi aktif bir şekilde teşvik edebildiğini ileri sürmüştür.

Robinson konu ile ilgili görüşlerini "girişim yol gösterir, finans takip eder" sözleriyle ifade etmiştir. Robinson'a göre bir ekonomide reel sektör genişledikçe finansal hizmetlere olan talebi artacak, artan talebe cevap vermeye çalışan finansal sektör böylece gelişecektir (Robinson, 1952: 86).

Goldsmith (1969) ise finansal gelişme ile ekonomik büyüme arasında pozitif ve güçlü bir nedensellik ilişkisi olduğunu göstermiş ve iktisat yazınında finansal gelişme ile ekonomik büyüme ilişkisinin ampirik kanıtlarını ilk ortaya koyan kişi olmuştur.

King ve Levine (1993) 60 ülkenin 1960 - 1980 dönemine ait verilerini kullanarak yaptıkları çalışmalarında finansal gelişmenin, ekonominin gelecekteki büyüme oranları, fiziki sermaye birikimi ve etkinlik artışı ile ilişkili olduğuna dair güçlü kanıtlar bulmuştur.

Thangevelu ve Jiunn'un (2004) Avusturya'ya ait verilerle yaptığı çalışmada finansal piyasalar ile finansal aracılık faaliyetlerinin ekonomik büyüme ile farklı yönlerde ilişkisi olduğuna dair kanttlar bulmuştur. Çalışma sonucuna göre finansal piyasaların gelişmesi ekonomik büyümeye neden olurken, ekonomik büyümeden finansal gelişmeye doğru bir nedensellik ilişkisine rastlanmamıştır. Yazarların farklı faiz oranları kullanarak yineledikleri duyarlılık testleri de ekonomik büyümenin finansal gelişmenin nedeni olduğuna dair sonuçlar üretmemiştir. Buna karşıllk yapılan testler ekonomik büyümenin finansal aracılı̆̆ın gelişmesine neden olduğu sonucunu ortaya koymuştur.

Teoride finansal gelişmişliğin ölçütü olarak çok sayıda değişken kullanılmaktadır. Ampirik çalışmalarda para veya kredi büyüklüklerini esas alan değişkenlerin yaygın olarak kullanıldığı görülmektedir. Uygulamada en çok kullanılan değişkenler: dar veya geniş tanımlı parasal büyüklükler (M1/GDP, M2/GDP), bankaların özel sektör alacaklarını GSYH'ya oranı, özel sektöre kullandırılan kredilerin GSYH'ya oranı, menkul kıymet borsasında faaliyet gösteren şirketlerin piyasa değerinin GSYH'ya oranı, M2/M1 oranıdır (Khan ve Qayyum, 2007; s. 7). 
Borsaları, yatırımcılar ve diğer finans kurumları için ikincil bir piyasa olanağı sağladığı için, bu piyasaların doğrudan katkı yapmasa da ekonomik büyümeyi desteklediğine işaret eden ampirik çalışmalar mevcuttur. Birçok kârlı yatırım, uzun vadeli bir sermaye taahhüdü gerektirir ancak tasarruf sahipleri, tasarruflarının kontrolünü uzun süre bırakmaya istekli değildir. Likit borsalar, bu isteksizliği, tasarruf sahiplerine hızlı ve ucuz bir şekilde satabilecekleri bir varlık sağlayarak ortadan kaldırırlar. Brunnermeier ve Pedersen (2009, s.2202) likit bir borsanın, büyük işlemlerin hisse senedi fiyatları üzerinde bir etki olmadan yapılabileceği piyasa olarak tanımlar.

Borsa gelişiminin ekonomik büyümeyi desteklediğini savunan çalışmaların sayısı son dönemde hızla artmaktadır. Yüksek likiditeye sahip borsalar, yatırımcıların şirketler hakkında bilgi edinmeleri ve kurumsal yönetişimi iyileştirmeleri için teşvikleri artırmaktadır (Holmstrom ve Tirole, 1993). Greenwood ve Smith (1997), büyük borsaların tasarrufların farklı finansal varlıklar arasında hareket etme maliyetini azaltabileceğini ve böylece üretken teknolojilere yatırım yapmayı kolaylaştırdığını ileri sürmüştür. Yartey ve Adjasi (2007), likit borsalarının yatırımcılara, projenin tamamlanmasından önce hisselerini kolayca, hızlı ve ucuz bir şekilde satma imkanı verdiğini, böylece uzun vadeli ve genellikle karlı projelere yatırım yapmayı teşvik ederek, sermaye tahsisini iyileştirip, uzun vadeli büyümeyi destekleyeceğini ileri sürmüştür. Bununla birlikte, kurumsal yönetim borsa likiditesinden olumsuz etkilenebilir. Çok likit piyasalar, yatırımcı miyopisini artırarak verimsiz işletme devralmalarına yol açıp büyümeye zarar verebilir.

Obstfeld (1994)'e göre uluslararası entegre borsalar yatırımcı riskini artırabilir, ancak aynı zamanda yatırımcılara uluslararası alanda çeşitlendirilmiş yatırım yapma konusunda daha fazla firsat sağlar. Her ülkenin küresel olarak çeşitlendirilmiş bir riskli yatırım portföyüne sahip olmasını sağlayan uluslararası finansal entegrasyon, tüm ülkeleri düşük getirili güvenli yatırımlardan yüksek getirili riskli yatırımlara yönelmeye teşvik etmektedir. Başlangıçta bazı risksiz varlıkların tutulması şartıyla, çeşitlendirme fırsatlarında küçük bir artış her zaman beklenen refahı ve ulusal refahı artırır. Buradaki kilit nokta, finansal serbestleşmenin net sermaye girişi olmasa bile büyümeyi artırabileceğidir. Yüksek likiditeye sahip borsalar da ekonomik büyüme ile pozitif ilişkilidir.

Benecivenga vd. (1995) borsa likiditesi, ekonomik büyüme oranı, verimlilik artışları ve sermaye birikimi değişkenlerini kullanarak yaptığı çalışmasında anılan değişkenler arasında güçlü ve pozitif bağlantı olduğunu ileri sürmüştür.

Levine ve Zervos (1998) bankac1lık sektörünün gelişmişliğini temsilen banka kredileri verilerini, borsa gelişmişliğini temsilen, volatilite, likidite ve dünya sermaye piyasasıyla entegrasyon göstergelerini kullanmıştır. Çalışma 
sonucunda, gelişmiş finansal piyasaların büyümeye hizmet ettiğini ancak süreçte borsa ve bankaların farklı işlevlere sahip olduklarını bulmuşlardır. Banka kredileri ve borsa likiditesi değişkelerinin birlikte bulunduğu regresyon analizlerinde her iki değişkenin de verimlilik artışı, büyüme ve sermaye birikimini pozitif etkilediği, borsanın büyüklüğ̈̈, volatilitesi ve uluslararası entegrasyon derecesi ile büyüme arasında ise güçlü bir ilişki olduğu tespit edilmiştir.

\section{VERİ VE YÖNTEM}

Bu çalışmada Türkiye için 1995:Q1 - 2018:Q1 dönemi verileri kullanılarak, finansal gelişme ile ekonomik büyüme arasındaki nedensellik ilişkisi araştırılmıştır. Finansal gelişmenin ölçütü olarak BIST-100 endeksinin likiditesi kullanılmıştır. Endeksin likiditesini ölçmek için ise en yaygın olarak kullanılan likidite ölçütlerinden Amihud (2002) likidite değişkeni tercih edilmiştir. Amihud likidite ölçütü 1 TL'lik bir işlem hacminin günlük fiyat değişimine etkisi olarak düşünülmektedir. Amihud likidite ölçütü matematiksel olarak aşağıdaki şekilde ifade edilir ${ }^{2}$ :

$$
\text { Amihud }_{q}=\frac{1}{D_{t}} \sum_{t=1}^{D_{t}} \frac{\mid \text { Getiri }_{t} \mid}{\text { İslem Hacmi }}
$$

Amihud $_{\mathrm{q}}$ BİST-100 endeksinin çeyrek dönemdeki likiditesini, Getiri ${ }_{\mathrm{t}}$ BIST100 endeksinin günlük getirisini ve İşlemHacmi ${ }_{t}$ BIST-100 endeksinin günlük işlem hacmini (fiyat*işlem miktarı) göstermektedir.

Likidite değişkenini oluşturmak için kullanılan BIST-100 işlem hacmi verileri Borsa İstanbul internet sitesinden, BIST-100 getiri verileri ise www.yahoo.finance and www.investing.com adreslerinden elde edilmiştir. Ekonomik büyüme değişkeni olarak ise Federal Reserve Bank of St Louis internet sitesinden çeyrek dönemlik Gayri Safi Yurt İçi Hasılanın büyüme oranı verisi kullanılmıştır. Ekonomik büyüme verisi bir önceki yılın aynı çeyreğine göre hesaplanmış ve mevsimsellikten arındırılmıştır. Ekonomik büyüme değişkeni ile benzer olması açısından Amihud likidite ölçüsü de bir önceki yılın aynı çeyreğine göre değişimi şeklinde hesaplanmıştır.

Yapılan çalışmalarda finansal gelişme göstergesi olarak birçok farklı değişken kullanıldı̆̆ 1 görülmektedir. $\mathrm{Bu}$ değişkenler genellikle para piyasasının likiditesinin gösteren M1, ve M2 olmaktadır. Bunlar ile birlikte semraye piyasasının likiditesini ölçmek için sıklıkla işlem hacminin GSYH oranı kullanılmaktadır (Tunalı ve Onuk, 2017). Sermaye piyasaları (özellikle borsalar) 2 Amihud (2002) likidite azlığını ölçmektedir. Amihud ölçütünün artması piyasada
likiditenin azaldığı anlamına gelmektedir. 
sermayenin tabana yayılmasını destekleyerek piyasanın canlanmasına destek vermektedir. Bununla birlikte yeni projelerin finanse edilmesi, büyüme ve modernleşmeye de katkı sağlamaktadır. Sayılan nedenlerden dolayı sermaye piyasalarının likiditesi, piyasanın doğru işlediğini ve verimli olduğunu gösteren bir ölçüt olarak kabul edilmektedir. Bu çalışmada sadece işlem hacmi değil bir likidite ölçütü olan Amihud (2002) kullanılmış ve Borsa İstanbul'un likiditesi ile ekonomik büyüme arasında bir ilişki olup olmadığı araştırılmıştır.

\section{ARAŞTIRMA BULGULARI}

Analize başlamadan önce ekonomik büyüme verisi mevsimsellikten arındırıldığı ve likidite verisi bir oranlamadan ortaya çıktığı için her hangi bir dönüşüm yapılmadan ham verilerin zaman serisi grafikleri incelenmiştir.

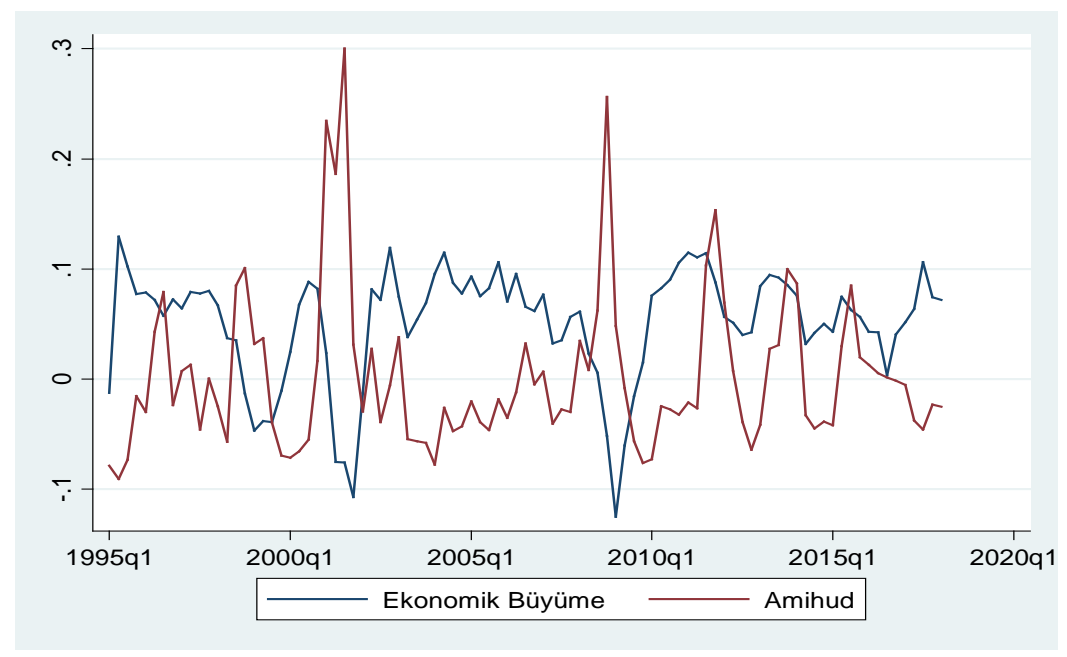

Grafik 1: Ekonomik Büyüme ve Amihud Değişkenleri Zaman Serisi Grafiği

Grafik 1'de görüldüğü gibi ekonomik büyüme ve Amihud değişkenlerinde herhangi bir trend söz konusu değildir. Bununla birlikte 1995, 2001 ve 2008 krizlerinde büyüme oranının negatif olduğu ve likiditenin de düştüğü gözlenmektedir. Büyüme oranının normalleştĭği dönemlerde ise likiditede artmış ve normal seviyelerde devam etmiştir. Sonuç olarak değişkenlere ait grafiklerden ekonomik büyüme ile likidite arasında pozitif yönlü bir ilişki olduğu anlaşılmaktadır. Ayrıca iki değişken arasındaki korelasyona hesaplamaları sonucunda korelasyon değeri -0.3465 (p-değeri=0.0007) olarak bulunmuştur. Bu da grafik üzerinde de görülen iki değişken arasındaki ilişkiyi desteklemektedir. 
Zaman serisi grafiği ve korelasyon hesaplamasından sonra değişkenler için birim kök testi yapılarak değişkenlerin durağanlılıkları test edilmiştir. $\mathrm{Bu}$ çalışmada birim kök testlerinden olan Phillips-Perron (PP) testi (1988) kullanılmıştır. PP testi otokorelasyonu dikkate alarak Newey-West standart sapmaları düzeltme yöntemini kullandığı için ampirik çalışmalarda yaygın bir şekilde tercih edilmektedir.

Tablo 1. Ekonomik Büyüme ve Amihud PP Birim Kök Testi

\begin{tabular}{|l|c|c|}
\hline Düzey Değeri & Sabitli & Sabitsiz \\
\hline Ekonomik Büyüme & $-4.356^{* * *}$ & $-2.810^{* * *}$ \\
& $(-3.520)$ & $(-2.603)$ \\
\hline Amihud & $-5.221^{* * *}$ & $-5.247^{* * *}$ \\
& $(-3.520)$ & $(-2.603)$ \\
\hline
\end{tabular}

*** 0.01 anlamlılık düzeyini ifade etmektedir. Kritik değerler parantez içerisinde gösterilmiştir.

PP birim kök testinde $\mathrm{H}_{0}$ (Null) hipotezinde değişkenlerin durağan olmadığı ve $\mathrm{H}_{1}$ (Alternatif) hipotezinde ise değişkenlerin durağan olduğu kabul edilmiştir. Tablo 1'de görüldüğ̈̈ gibi test değerleri kritik değerlerden daha yüksektir. Bu durumda $\mathrm{H}_{0}$ hipotez reddedilmiş ve iki değişkenin de düzey de durağan olduğu kabul edilmiştir. Yani değişkenlerde birim kök problemi olmadığ 1 tespit edilmiştir.

Değişkenlerin durağanl1lık seviyelerini tespit ettikten sonra VAR modelini uygulayabilmek için gerekli olan gecikme değerlerinin tespiti için 4 farklı kriter uygulanmıştır. Tablo 2'ye bakıldığında zaman değişkenleri için gecikme değerinin FPE ve AIC kriterleri için 4, HQIC kriteri için 2 ve SIC kriteri için 1 olduğu gözlemlenmiştir. Bu durumda literatürde daha önce yapılmış çalışmaları takip ederek Akaike Bilgi Kriteri tercih edilmiştir. Bu nedenle gecikme değeri olarak VAR analizinde 4 gecikme uygulanmıştır.

Tablo 2. Ekonomik Büyüme ve Amihud için Gecikme Değerleri

\begin{tabular}{|c|c|c|c|c|}
\hline Gecikme & FPE & AIC & HQIC & SIC \\
\hline 0 & 0.000012 & -5.66632 & -5.64433 & -5.61185 \\
\hline 1 & $2.00 \mathrm{E}-06$ & -7.43582 & -7.36984 & $-7.27242^{*}$ \\
\hline
\end{tabular}




\begin{tabular}{|c|c|c|c|c|}
\hline 2 & $1.90 \mathrm{E}-06$ & -7.48457 & $-7.37461^{*}$ & -7.21224 \\
\hline 3 & $2.00 \mathrm{E}-06$ & -7.44774 & -7.2938 & -7.06649 \\
\hline 4 & $1.9 \mathrm{e}-06^{*}$ & $-7.49857^{*}$ & -7.30065 & -7.00839 \\
\hline
\end{tabular}

FPE: Final Prediction Error Kriterini, AIC: Akaike Bilgi Kriterini, HQIC: Hanna-Quinn Bilgi Kriterini ve SBIC: Schwartz Bilgi Kriterini ifade etmektedir.

Değişkenlerin durağanlık seviyeleri tespit edildikten sonra aralarındaki nedensellik ilişkisini bulmak için Granger nedensellik testi (1969) uygulanmıştır. Çalışmanın modeli şu şekilde formüle edilmiştir:

Ekonomik Büyüme $_{t}=\sum_{j=1}^{4} \delta_{j}$ Amihud $_{t-j}+$

$$
\sum_{j=1}^{4} \theta_{j} \text { Ekonomik Büyüme } e_{t-j}+\varepsilon_{t}
$$

$$
\text { Amihud }_{t}=\sum_{j=1}^{4} \mu_{j} \text { Amihud }_{t-j}+\sum_{j=1}^{4} \gamma_{j} \text { Ekonomik Büyüme }_{t-j}+\varphi_{t}
$$

Eşitlik 2 ve 3 de berlitilen regresyon fonksiyonlarının $\mathrm{H}_{0}$ hipotezleri $\sum_{j=1}^{4} \delta_{j}=0$ ve $\sum_{j=1}^{4} \gamma_{j}=0$ olarak gösterilmektedir. Başka bir ifade ile eşitlik 2 'deki H0 hipotezi: Likidite artış1 ekonomik büyümenin nedeni değildir ve eşitlik 3'de H0 hipotezi: Ekonomik Büyüme likidite artışının nedeni değildir diye açılanabilir. Alternatif hipotezler ise iki değişken arasında nedenselliğin olduğu durumları ifade etmektedir.

\begin{tabular}{|c|c|c|c|}
\hline $\begin{array}{l}\text { Granger Nedensellik } \\
\text { Hipotezleri }\end{array}$ & $\chi^{2}$ & $\begin{array}{c}\mathrm{p}- \\
\text { değeri }\end{array}$ & Karar \\
\hline $\begin{array}{l}\text { Ekomik Büyüme } \\
\text { likidite artışının } \\
\text { Granger Nedeni } \\
\text { Değildir }\end{array}$ & 2.6561 & 0.617 & $\begin{array}{c}\text { Ekonomik büyümeden } \\
\text { likidite artışına doğru } \\
\text { nedensellik yoktur. }\end{array}$ \\
\hline $\begin{array}{l}\text { Likidite artışı } \\
\text { Ekonomik Büyüme’nin } \\
\text { Granger Nedeni } \\
\text { Değildir }\end{array}$ & $78.853 * * *$ & 0.000 & $\begin{array}{l}\text { Likidite artışından ekonomik } \\
\text { büyümeye doğru \%1 } \\
\text { anlamlılık seviyesinde } \\
\text { nedensellik vardır. }\end{array}$ \\
\hline
\end{tabular}

Tablo 3. Granger Nedensellik Sonuçları

*** 0.01 anlamlılık düzeyini ifade etmektedir.

Tablo 3'teki ki-kare ve anlamlılık değerlerine bakıldığında, ekonomik büyümeden likidite artışına doğru bir Granger nedensellik olmadığ 1 fakat likidite 
artışından ekonomik büyümeye doğru \%1 seviyesinde anlamlı bir Granger nedensellik olduğu görülmektedir.

Tablo 4. VAR Modeli Tahmin Sonuçları

\begin{tabular}{|c|c|c|c|}
\hline \multicolumn{2}{|c|}{$\begin{array}{l}\text { Bağımlı Değişken Ekonomik } \\
\text { Büyüme }\end{array}$} & \multicolumn{2}{|c|}{ Bağımlı Değişken Amihud Likidite } \\
\hline $\begin{array}{l}\text { Ekonomik Büyüme(- } \\
\text { 1) }\end{array}$ & $\begin{array}{c}0.792^{* * *} \\
(0.000)\end{array}$ & Ekonomik Büyüme(-1) & $\begin{array}{l}-0.153 \\
(0.532)\end{array}$ \\
\hline $\begin{array}{l}\text { Ekonomik Büyüme(- } \\
\text { 2) }\end{array}$ & $\begin{array}{l}-0.058 \\
(0.636)\end{array}$ & Ekonomik Büyüme(-2) & $\begin{array}{c}0.005 \\
(0.987)\end{array}$ \\
\hline $\begin{array}{l}\text { Ekonomik Büyüme(- } \\
\text { 3) }\end{array}$ & $\begin{array}{c}0.081 \\
(0.449)\end{array}$ & Ekonomik Büyüme(-3) & $\begin{array}{c}0.341 \\
(0.195)\end{array}$ \\
\hline $\begin{array}{l}\text { Ekonomik Büyüme(- } \\
\text { 4) }\end{array}$ & $\begin{array}{l}-0.146 \\
(0.043)\end{array}$ & Ekonomik Büyüme(-4) & $\begin{array}{l}-0.266 \\
(0.134)\end{array}$ \\
\hline Amihud(-1) & $\begin{array}{c}-0.345^{* * *} \\
(0.000)\end{array}$ & Amihud(-1) & $\begin{array}{c}0.555^{* * *} \\
(0.000)\end{array}$ \\
\hline Amihud(-2) & $\begin{array}{c}0.146^{* * *} \\
(0.009)\end{array}$ & Amihud(-2) & $\begin{array}{l}-0.067 \\
(0.620)\end{array}$ \\
\hline Amihud(-3) & $\begin{array}{l}0.012 \\
(0.815)\end{array}$ & Amihud(-3) & $\begin{array}{l}-0.013 \\
(0.919)\end{array}$ \\
\hline Amihud(-4) & $\begin{array}{c}0.050 \\
(0.263)\end{array}$ & Amihud(-4) & $\begin{array}{c}-0.239 * * \\
(0.031)\end{array}$ \\
\hline Sabit Terim & $\begin{array}{c}0.017^{* * *} \\
(0.000)\end{array}$ & Sabit Terim & $\begin{array}{c}0.006 \\
(0.547)\end{array}$ \\
\hline $\mathrm{R}^{2}$ & 0.819 & $\mathrm{R}^{2}$ & 0.439 \\
\hline
\end{tabular}




\begin{tabular}{|l|c|l|c|}
\hline Ki-Kare & $\begin{array}{c}422.268^{* * *} \\
(0.000)\end{array}$ & Ki-Kare & $72.845^{* * *}$ \\
& & & $(0.000)$ \\
\hline
\end{tabular}

$* * * 0.01,{ }^{* *} 0.05$ ve $* 0.10$ anlaml1l1k düzeyini ifade etmektedir.

Tablo 4'te Vector Autoregression (VAR) modeli sonuçları verilmiştir. Regresyon sonuçlarına göre Amihud değişkeni ile ekonomik büyüme değişkeni arasında negatif bir ilişkinin var olduğu görülmektedir. Yani likidite artışı ekonomik büyümeyi pozitif etkilemektedir. Ancak bağımlı değişkenin likidite olduğu modelde ekonomik büyümenin likidite üzerinde anlamlı bir etkisinin olmadığı görülmektedir.

\section{Etki-Tepki (Impulse-Response) Fonksiyonları}

VAR modelinin sonuçlarının anlamlı yorumlanabilmesi için gerekli olan etkitepki fonksiyonu değişkenlerden birinde yaşanabilecek bir şokun diğer değişken üzerindeki etkilerini anlamak için kullanılmaktadır. Bu çalışmada da etki-tepki analizi uygulanmış ve çıkan sonuçlar Grafik 2. ve Grafik 3.'te sunulmuştur.

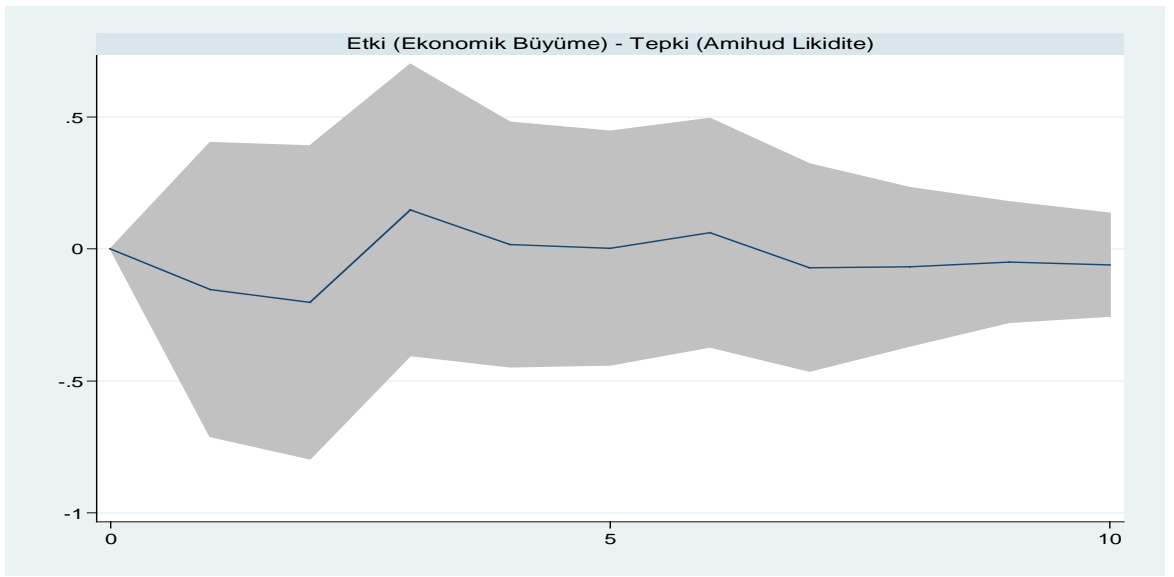

\section{Grafik 2. Etki-Tepki Grafiği}

Grafik 2'de ekonomik büyümede yaşanacak bir şokun amihud likidite ölçüsünde nasıl bir tepkiye yol açacağı gösterilmiştir. Grafikte görüldüğü gibi ekonomik büyüme de oluşacak bir birimlik şok amihud likidite ölçüsünde herhangi bir değişime neden olmamaktadır. Bu da Granger nedensellik analizinde bulunmuş olan sonucu desteklemektedir. 


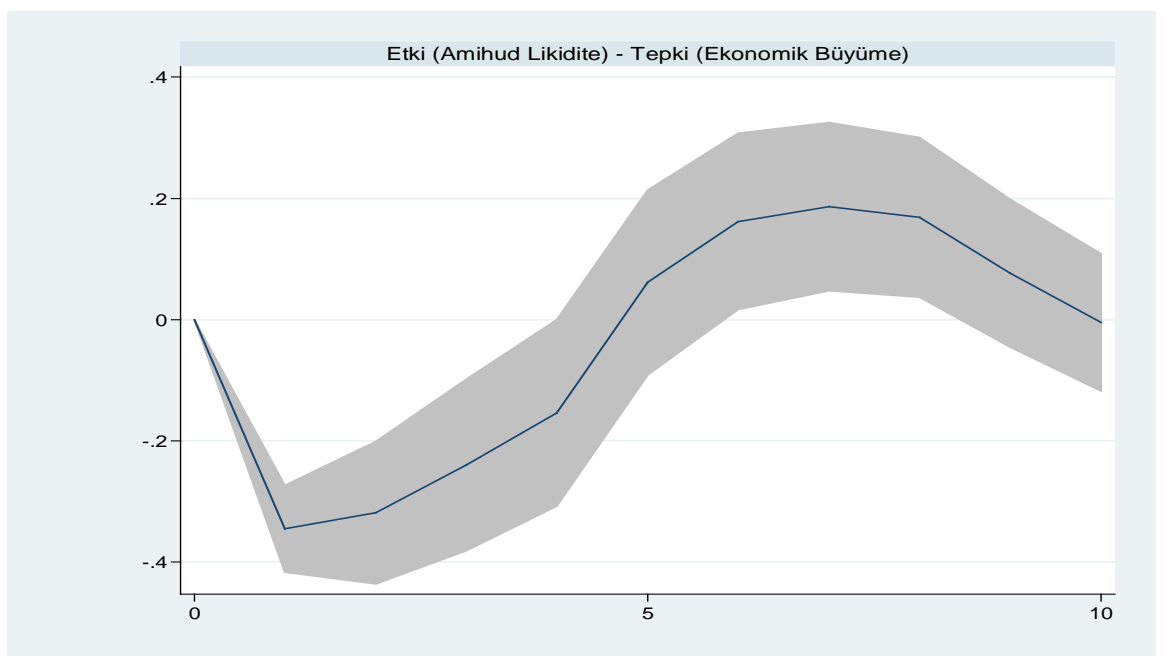

Grafik 3. Etki-Tepki Grafiği

Grafik 3'te Amihud likidite ölçütünde yaşanacak bir şokun ekonomik büyümede nasıl bir tepkiye yol açacağı gösterilmiştir. Grafikte görüldügüu üzere amihud likidite ölçüsünde oluşacak bir birimlik pozitif şok ekonomik büyümenin azalmasına neden olmaktadır. Bu azalış ilk iki çeyrek devam etmekte sonrasında ekonomik büyüme yavaş yavaş şok öncesi seviyesine geri dönmektedir. 1 birimlik pozitif şok ilk çeyrekte -0.345 ve ikinci çeyrekte -0.318 standart sapmalık bir azalışa neden olmaktadır. Diğer bir ifade ile likiditede oluşacak bir artı̧̧ ekonomik büyümeye pozitif yönde etki sağlayacaktır. Bu etki Granger nedensellik analizinde daha önce elde edilmiş olan sonuç ile de örtüşmektedir.

\section{SONUÇ}

Finansal sistemin gelişmesinin ekonomik büyümeye olan etkileri birçok araştırmanın konusunu olmuştur. Finansal gelişme, araştırmacılar tarafından birçok farklı değişken ile tahmin edilmeye çalışılmıştır. Bu değişkenlerin büyük çoğunluğu para piyasaları araçları ile ilgili olmuştur. Bu çalışmada ise finansal gelişme sermaye piyasası araçlarından hisse senedi likiditesi ile tahmin edilmeye çalışılmış ve ekonomik büyüme ile arasındaki ilişki Borsa İstanbul özelinde incelenmiştir. Çalışmada 1995Q1 - 2018Q1 dönemleri arasında üçer aylık Gayri safi yurt içi hasıla büyüme oranı ve BİST-100 endeksinin Amihud likidite ölçüsü kullanılmıştır. Ekonomik büyüme ve finansal gelişme arasındaki ilişki Granger nedensellik yöntemi ile incelenmiş ve likiditeden ekonomik büyümeye doğru bir nedensellik olduğu tespit edilmiştir. Bu sonuç VAR analizi ve impulse-response fonksiyonları ile de desteklenmiştir. 
Levin and Zervos (1996) likiditenin ekonomik büyümeyi etkileyen en önemli faktörlerden biri olduğunu savunmuştur. Ekonomik büyümeyi sağlayacak karlı yatırımlar genel olarak uzun dönemde elde edilmektedir. Bu uzun dönemli yatırımları yapabilmek için gerekli olan fonları bulma yolunda sermaye piyasaları en çok tercih edilen kuruluşlar olarak karşımıza çıkmaktadır. Tasarruf sahipleri yatırımlarının güvenli ve istedikleri zaman nakite çevirebilecekleri yatırım araçlarında tutmayı tercih ederler. Bu nedenle para kaybetmeden ve hızlıca işlem yapmak anlamına gelen likidite yatırımcılar açısından önemli bir gösterge olmaktadır. Piyasalar eğer likit ise yatırımcılar uzun dönemli yatırımları finanse etmekte ve bu da ekonomik büyümeyi doğrudan etkilemektedir.

Ekonomik gelişmeyi sürekli hale getirmek için gerekli olan yatırımların finansmanına aracilık eden en önemli kurum olan borsaların likiditesinin artırılması tasarruf sahiplerinin tasarruflarını borsada kullanması sağlar. Tasarruf sahiplerinin yatırımlarını yastık altında tutmak yerine ihtiyaç duydukları anda nakde çevirebileceğini bildikleri bir yatırım aracına yönelmeleri hem ekonomiden sızıntıları engelleyecek hem de yatırımcıya düşük maliyetle uzun vadeli yatırımlarını finanse etme olanağı sağlayacaktır. Böyle bir ortamda firmalar büyük yatırımları için yüksek faiz oranlı fonlar yerine borsadan sağlayacakları fonlar ile yapabileceklerdir.

\section{KAYNAKÇA}

Al-Yousif, Y. Khalifa (2002), "Financial Development and Economic Growth: Another Look at the Evidence from Developing Countries", Review of Financial Economics, Vol. 11, Issue 2, ss. 131-150.

Amihud, Yakov (2002), "Illiquidity and stock returns: cross-section and timeseries effects”, Journal of Financial Markets, Vol. 5, Issue 1, ss. 31-56.

Aziz, Jahangir, and Christoph Duenwald (2002), Growth-Finance Intermediation Nexus in China, IMF Working Paper No. WP/02/194, International Monetary Fund: Washington D.C.

Bencivenga, Valeria, Smith, Bruce, and Starr, Ross (1995), "Equity Markets, Transaction Costs, and Capital Accumulation: An Illustration”, The World Bank Economic Review, Vol. 10, Issue 2, ss. 241-265.

Brunnermeier, Markus, and Pedersen, Lasse (2009), "Market Liquidity and Funding Liquidity”, Review of Financial Studies, Vol.22, Issue 6, ss. 2201-2238. 
Furstenberg, George, and Fratianni, Michele (1996), "Indicators of financial development”, North American Journal of Economics and Finance, Vol. 7, Issue 1, ss. 19-29.

Gertler, Mark, and Andrew Rose (1994), Finance, Public Policy, and Growth. ss. 13-48 in Financial Reform: Theory and Experience, edited by Gerard Caprio, Izak Atiyas, and James A. Hanson. Cambridge, MA: Cambridge University Press.

Goldsmith, Raymond W. (1969), Financial Structure and Economic Development (Study In Comparative Economics),: Yale University Press, New Haven, 561 p.

Granger, Clive (1969), “Investigating Causal Relations by Econometric Models and CrossSpectral Methods”, Econometrica, Vol. 37, Issue 3, ss. 424-438.

Greenwood, Jeremy, and Smith Bruce (1997), "Financial markets in development, and the development of financial markets”, Journal of Economic Dynamics and Control, Vol. 21, Issue 1, ss.145-181.

Holmstrom, Bengt, and Tirole, Jean (1993), "Private and Public Supply of Liquidity”, Journal of Political Economy, 1998, Vol. 106, Issue 1, ss. 140.

Khan, Muhammad Arshad and Qayyum, Abdul (2007), “Trade, Financial and Growth Nexus in Pakistan”, Pakistan Institute of Development Economics Islamabad Pakistan, MPRA, Economic Analysis Working Papers. Paper No. 65236th, Volume 14, pp.25.

King, Robert, and Levine, Ross (1993), "Finance and Growth: Schumpeter Might be Right The”, Quarterly Journal of Economics, Vol. 108, Issue 3, ss. 717-737.

Kirkpatrick, Colin, and Green, Christopher (2002), “Finance and Development: An Overview of the Issues”, Journal of International Development, Vol. 14, Issue 2, ss. 207-209.

Levine, Ross, and Zervos, Sara (1996), “Stock Market Development and LongRun Growth”, The World Bank Economic Review, Vol. 10, Issue 2, ss. 323-339.

Levine, Ross, and Zervos, Sara (1998), "Stock Markets, Banks and Economic Growth”, The American Economic Review, Vol. 88, Issue 3, ss. 537-558. 
Obstfeld, Maurice (1994), “Risk-Taking, Global Diversification, and Growth.” American Economic Review, Vol. 84, Issue 5, ss. 1310-1329.

Patrick, Hugh, T. (1966), "Financial Development and Economic Growth in Underdeveloped Countries", Economic Development and Cultural Change, Vol. 14, ss.174-189.

Phillips, Peter, and Perron, Pierre (1988), “Testing for a unit root in time series regression”, Biometrika, Vol. 75, Issue 2, ss. 335-346.

Robinson, Joan (1952), “The Generalization of the General Theory”, in The Rate of Interest, and Other Essays, London: Macmillan, ss. 67-142.

Schumpeter, Joseph A. (1911), The Theory of Economic Development: An Inquiry Into Profits, Capital, Credit, Interest, and the Business Cycle, (Translation of: Theorie der wirtschaftlichen Entwicklung. Reprint. Originally published: Cambridge, Mass.: Harvard University, 1934), Routledge, London and New York, 2017, 320 p.

Thangavelu, Shandre M., and Ang, Beng Jiunn \& James, (2004), “Financial Development and Economic Growth in Australia: An Empirical Analysis”, Empirical Economics, Vol. 29, Issue 2, ss. 247-260.

Tunal1, Halil ve Onuk, Parla (2017), "Finansal Gelişme ve Ekonomik Büyüme Arasındaki Nedensellik İlişkisi: Türkiye Örneği’, İktisat Politikası Araştırmaları Dergisi, Vol. 4, Issue 1, ss. 1-15.

Yartey, Charles, and Adjasi, Charles (2007), "Stock Market Development in Sub-Saharan Africa: Critical Issues and Challanges”, International Monetary Fund Working Paper WP/07/209.Washington DC. United States of America. 